
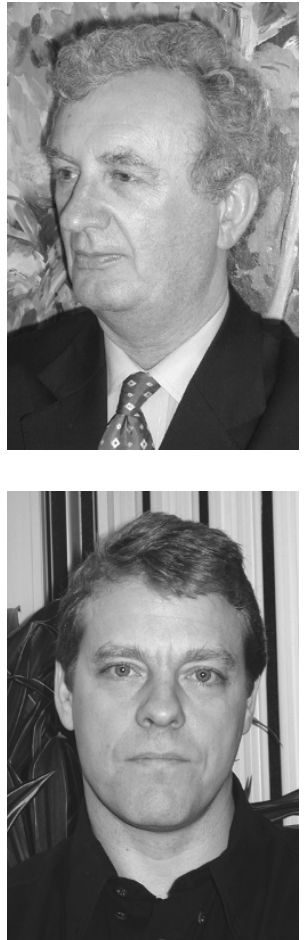

\title{
CRM systems: Necessary, but not sufficient. REAP the benefits of customer management
}

Received (in revised form): 4th December, 2001

\section{Michael Starkey}

is a senior lecturer in marketing at De Monfort University with specialist interest in customer management, and improving business performance. He has conducted customer management performance assessments using the research version of QCi's Customer Management Assessment Tool (CMAT) in North America, Asia-Pacific and Europe.

Michael is the author/co-author of more than 25 publications and has had papers published in Long Range Planning, Journal of Database Marketing, Marketing Business, Training for Quality and TQM Magazine.

\section{Neil Woodcock}

is chairman of specialist customer management consultancy QCi Ltd. He worked in client-side consumer and industrial sales, sales management and marketing planning roles before joining Andersen Consulting in 1985 . He joined the forerunner to QCi in the late 1980s and has been consulting in various aspects of customer management with many of the world's largest companies since then. He is on the editorial boards of the International Journal of Customer Relationship Marketing and the Journal of Database Marketing and is a frequent speaker on various aspects of CM.

Abstract Research shows that there is a good correlation between customer management (CM) performance and business performance. Expenditure on customer relationship management (CRM) information technology (IT) systems has increased over the years, however many CRM systems fail to deliver the desired objectives. Actual CM performance measured using CMAT ${ }^{\mathrm{TM}}$ (Customer Management Assessment Tool) is, however, disappointing and companies may be destroying rather than creating economic value. Investment in REAP (Retention, Efficiency, Acquisition and Penetration) measures can provide a four to one return on investment for well-managed programmes.

\section{INTRODUCTION}

Spending on CRM has continued to grow. Research shows first, that there is a correlation between customer management (CM) performance and business performance and secondly, that actual performance in customer management is not improving. Some companies are wasting opportunities and are more likely to be destroying economic value from their CM effort. This paper identifies some of the reasons for this and puts forward the business case for customer management.

\section{CUSTOMER MANAGEMENT SPENDING}

Even after the start of the economic slowdown beginning in early 2001 Gartner was predicting ${ }^{1}$ that worldwide spending on CRM would reach US $\$ 76.3 \mathrm{bn}$ in 2005 , up from the $\$ 23.26$ bn achieved in 2000. Licence revenue would continue to be around 16 per cent of this total revenue. The North American share of spending was estimated to drop from 67 per cent to 48 per cent of total spending during 2000-2005, as Europe and Asia 
increasingly focus on CRM. Spending was predicted to increase even though there has been a high CRM

(technology) failure rate ${ }^{2}$ and according to Gartner 55 per cent of all CRM and e-CRM projects will fail to meet benefit objectives and to effect positively return on investment (ROI). Forrester Research $^{4}$ suggests that 57 per cent of all companies that took part in a survey said they "could not justify the investment in customer service programmes because of the difficulty of measuring the impact on profitability'.

The events of 11th September, 2001 have had a negative effect on many industry sectors including the CRM technology industry, which had until then bucked the trend of a general economic downturn. A Gartner report by Thomas Topolinski ${ }^{5}$ entitled 'The impact of 11th September on CRM software vendors' paints a grim picture and suggests the effect will range from extinction for some to mild growth. The winners will shift to marketing and deployment tactics that deliver customer ROI and financial tactics to maintain shareholder value. The report describes how market leader Siebel saw its new licence revenue decline in the third quarter 2001 by 37 per cent compared with the same quarter for the previous year. Kana suffered a 92 per cent decline and Broadvision a 73 per cent decline compared to the third quarter of 2000. The issue of whether CRM applications software projects deliver value has been take up in an editorial of crm-forum.com and it refers to 'the trough of disillusionment'. The editorial, in referring to a CRM vendor announcement states

\footnotetext{
'What was disappointing at the announcement was a presentation by Tom Siebel, with only one, rather flaky, slide on the benefits of CRM, and no detail at all
}

- even when challenged. This during an announcement that recognised client-side concerns on the value of CRM. One rather suspects that this lack of focus on benefits is because Siebel have no firm evidence of them. We'd be delighted to be proved wrong on this, and if Siebel Systems care to send us detailed case studies of how they deliver benefits to their clients from their system, we'd be delighted to publish them'.

Peter Doyle ${ }^{7}$ of Warwick Business School refers to the confusion managers have sometimes shown between maximising shareholder value and maximising profitability. Doyle states that the two are completely different and that

\footnotetext{
'Maximising profitability is short term and invariably erodes the company's long-term market competitiveness. It is about cutting costs and shedding assets to produce quick improvements in earnings. By neglecting new market opportunities and failing to reinvest, such strategies destroy rather than create economic value. Strategies aimed at maximising shareholder value are different. They focus on identifying growth opportunities and building competitive advantage. They punish short-term strategies that destroy assets and fail to capitalise on the company's core capabilities'.
}

Good customer management is important and helps deliver shareholder value as there is a strong correlation (0.8) between customer management ${ }^{8}$ performance using the Customer Management Assessment Tool $^{\mathrm{TM}}$ $(\mathrm{CMAT})^{9}$ and business performance. The highest correlation is with the people and organisation, measurement and customer management activities elements of the model (see Figure 1). A full description of the model and CMAT can be found in the authors' reports. ${ }^{10,11}$ But their research ${ }^{12}$ indicates that overall performance is not improving. 


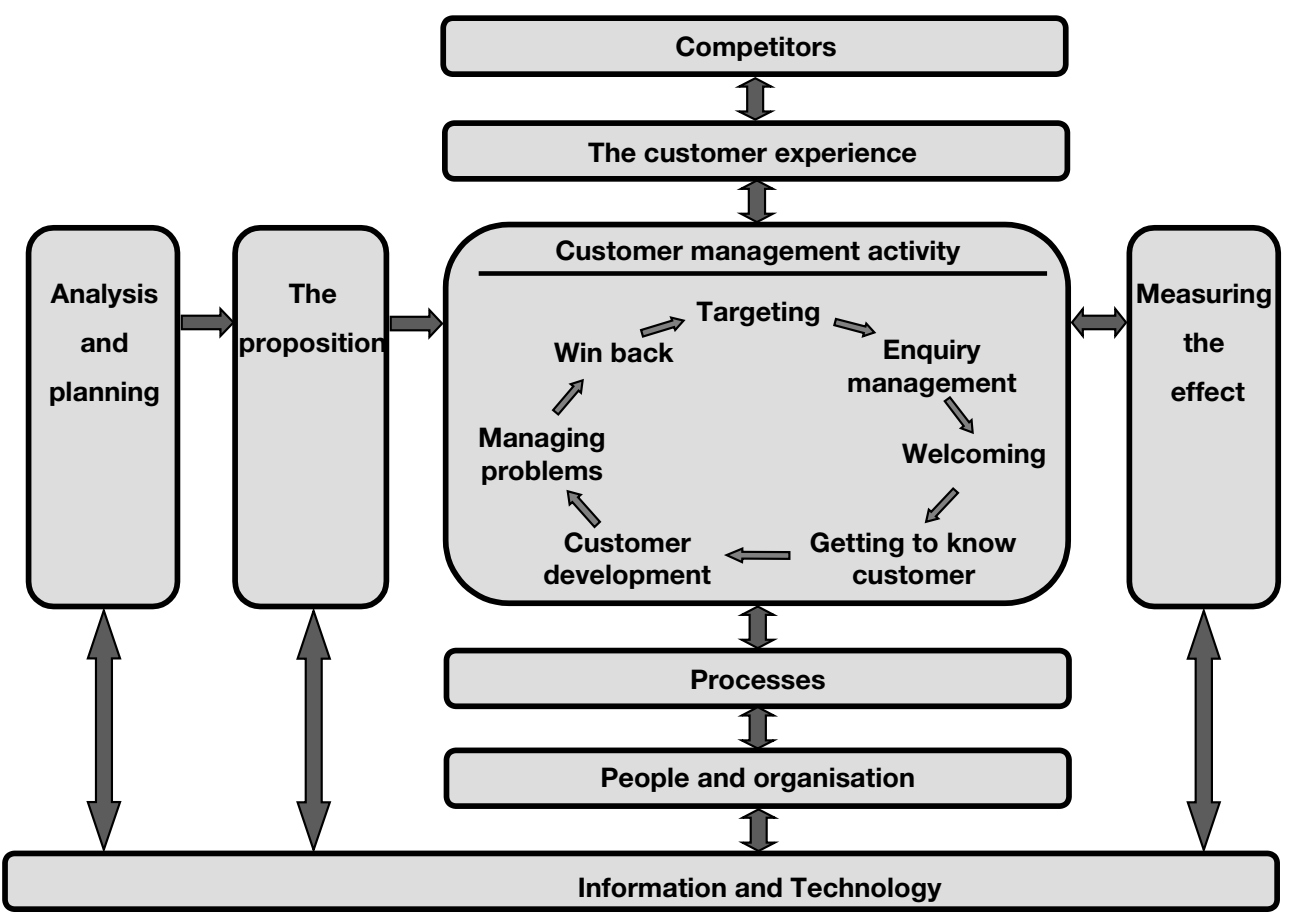

Figure 1: The QCi customer management model CQQCi Assessment Ltd

\section{CUSTOMER MANAGEMENT PERFORMANCE IS DISAPPOINTING}

The average CMAT score is 33 per cent. This means, in CMAT scoring terms, 'some commitment, some progress'. In most cases, this means that progress is patchy, uncertain and unconvincing and therefore unlikely to have a solid and permanent effect on business performance.

\section{PERFORMANCE IS NOT IMPROVING, BUT PROBABLY DECLINING}

Companies appear to be experiencing real problems in implementing CM. Spend on CRM is estimated to have trebled over the last three years, but the overall level of competence in customer management seems to be falling. At best, companies are wasting an opportunity. At worst, they are destroying value and/or investing in failure. The 'destroying value' comment (see Table 1) does not refer to all companies. The authors' business case studies show that some companies investing in customer management have increased value in the period. In comparing the performance of two sample sets of similar companies over time, however, it can be seen that general competency in the area of customer management has not improved, and has even decreased. Generally, companies are, despite the hype and investment, more likely to be destroying economic value from their customer management effort.

\section{WHY HAVE THE SCORES DECLINED?}

Although it cannot necessarily be inferred that individual companies' scores are declining, as only a few companies have been assessed twice in three years, the overall fall in scores is worrying. It 
Table 1: Creating and destroying customer value

\begin{tabular}{|c|c|c|c|}
\hline & $\begin{array}{l}\text { Period } 1 \\
\%\end{array}$ & $\begin{array}{l}\text { Period } 2 \\
\%\end{array}$ & $\begin{array}{l}\text { Comment on whether value is } \\
\text { being created or destroyed }\end{array}$ \\
\hline Analysis and planning & 30 & 27 & Some destruction of value \\
\hline Overall customer management planning & 28 & 25 & Some destruction of value \\
\hline Planning for customer acquisition & 27 & 18 & Value being destroyed \\
\hline Planning for customer retention & 30 & 35 & Created \\
\hline Planning for customer development & 24 & 25 & \\
\hline Understanding competition & 49 & 41 & Value being destroyed \\
\hline Knowledge management & 23 & 16 & Value being destroyed \\
\hline The proposition & 30 & 27 & Some destruction of value \\
\hline Developing the proposition & 33 & 30 & Some destruction of value \\
\hline Communicating the proposition & 33 & 29 & Value being destroyed \\
\hline People and organisation & 40 & 39 & No real change \\
\hline Creating the organisation & 43 & 38 & Value being destroyed \\
\hline Managing your people & 40 & 38 & Some destruction of value \\
\hline Managing suppliers & 38 & 40 & Some creation of value \\
\hline Information and technology & 40 & 35 & Value being destroyed \\
\hline Acquiring customer information & 49 & 43 & Value being destroyed \\
\hline Managing customer information & 32 & 28 & Value being destroyed \\
\hline Current system functions & 32 & 36 & Created \\
\hline Developing new systems & 52 & 38 & Value being destroyed \\
\hline Process management & 30 & 31 & No real change \\
\hline Ongoing process management & 32 & 29 & Some destruction of value \\
\hline Process improvement & 32 & 35 & Some creation of value \\
\hline Customer management activity & 33 & 32 & No real change \\
\hline Targeting & 30 & 30 & No real change \\
\hline Enquiry management & 40 & 40 & No real change \\
\hline Welcoming & 29 & 30 & No real change \\
\hline Getting to know/Healthcheck & 25 & 21 & Value being destroyed \\
\hline Ongoing management & 28 & 30 & Some creation of value \\
\hline Managing dissatisfaction & 42 & 40 & Some destruction of value \\
\hline Winback & 21 & 9 & Value being destroyed \\
\hline Measuring the effect & 35 & 36 & No real change \\
\hline Measuring customer management overall & 31 & 30 & No real change \\
\hline Measuring the effect of campaigns & 37 & 35 & Some destruction of value \\
\hline Measuring the effect of channels & 37 & 39 & Some creation of value \\
\hline Measuring the effect of individuals & 37 & 39 & Some creation of value \\
\hline The customer experience & & & \\
\hline Understanding satisfaction and loyalty & 34 & 25 & Value being destroyed \\
\hline Experiencing what customers experience & 27 & 26 & No real change \\
\hline Using benchmarks & 33 & 34 & No real change \\
\hline${ }^{\star}$ Comment index and criteria & \multicolumn{3}{|c|}{ Occurs when } \\
\hline Some destruction of value & \multirow{7}{*}{\multicolumn{3}{|c|}{$\begin{array}{l}<1 \% \text { and }<4 \% \text { less in current period than last } \\
>1 \% \text { and }<4 \% \text { less in current period than last } \\
\text { performance is } 4 \% \text { or more worse than last year } \\
\text { performance is } 4 \% \text { or more better than last year } \\
\text { two periods are within } 1 \% \text { of each other either way } \\
>4 \% \text { lower than last period } \\
>4 \% \text { higher than last period }\end{array}$}} \\
\hline Some creation of value & & & \\
\hline Value being destroyed & & & \\
\hline Value being created & & & \\
\hline No real change & & & \\
\hline Figures in italic & & & \\
\hline Figures in bold & & & \\
\hline
\end{tabular}

Source: Woodcock et al. (see ref. 11)

could, of course, be due to the possibility that the companies assessed initially were those most interested in CRM, while those assessed later were actually later entrants into CRM. In fact, this is not true. Many of the companies assessed later had been involved in CRM and similar approaches for ten or more years, some were indeed household names for the quality of at least some of their CM activities. Table 1 illustrates the areas where customer management competence has increased and declined. Because of the clear correlation between each area of the CMAT model with business performance, ${ }^{13}$ the table also 
shows where customer management value is being created and destroyed.

\section{WHY ARE COMPANIES PERFORMING SO POORLY, DESPITE THE INVESTMENT?}

The findings in this report have led the authors to the following conclusions.

\section{Senior executive ownership and leadership is required}

This appears to be less of an issue now than it was, although still only one in five companies have executives on the board with responsibility for CRM (ie constituting more than 50 per cent of their role). But the research results show that, as yet, these executives are not increasing their companies' CM effectiveness. Why? The authors' explanation of this is as follows:

- managers have a short-term focus: financial objectives are often set quarterly or at best annually. CM approaches often take longer to pay back, unless activities are carefully planned. Managers are often in a role as a stepping stone 'career development' move, and their performance in a function is only judged over a short period of time

- managers do not see change through. For example, investment in CM systems is clearly taking place, but it appears that not enough is invested in changing the behaviour and attitudes of employees, so little actually changes

- senior managers ignore the basics of what defines good CM and business performance. Some consultants and senior managers are obsessed with 'dramatic change' and new concepts. Plans that take a company's current business model, tighten it up in places and adapt it slightly in others, do not seem to appeal to managers obsessed with dramatic change. Unfortunately, there are just too many of these managers, and some consultancy firms encourage this attitude and even feed on it. The authors' research shows that significant benefits can be achieved more quickly and easily, and certainly more cheaply, through incremental change, often fixing areas that senior management do not know are broken

- senior managers do not recognise their companies' CM strengths and weaknesses. The research shows that senior managers' views on their company's strengths and weaknesses are often different before and after a $\mathrm{CMAT}^{\mathrm{TM}}$. So, project priorities and implementation programmes developed without a thorough review of the current position are likely to be founded on myths

- senior managers appear to rarely have the real authority or appetite to challenge the status quo and work across the enterprise.

\section{Too much thinking, too little doing}

Analysis ${ }^{14}$ shows the cerebral nature of enterprises. Companies make CM too complicated. Too much time is spent defining strategy and programmes, too little implementing them. It is easy to postulate and theorise, much harder to deliver. Complication occurs in part because, typically, CM approaches are designed by committees, often removed from the reality of customers. Processes become over-engineered to cope with the most complex situation, and become difficult to use.

\section{Functional and departmental silos}

Customer management is still implemented by functions and departments, even though there is an 
increasing use of enterprise-wide systems. This siloed approach does not support building value through the various stages of CM; from analysis and planning through to people. This approach is also dysfunctional from the perspective of customers, who expect to be managed consistently across departments.

\section{Great is small!}

Larger companies find it more difficult to manage customers than smaller companies do. The authors' research appears to confirm this. Though this report does not examine why this is the case (more research is needed), many reasons come to mind. For the moment, however, larger companies could themselves examine why smaller companies do better.

\section{CM is 'champion' based}

CM behaviours (eg customer profitability analysis and managing customers based on their value) are often not embedded in the culture of an organisation. Hence, people change roles and their thinking is either lost or moves with them. The authors have seen examples of this in companies that have repeated a $\mathrm{CMAT}^{\mathrm{TM}}$ after a year or so. Scores often fall in a previously high scoring area because the relevant senior manager or a key player in the particular area has moved on.

\section{More education required}

Knowledge of good customer management techniques and practices is not widespread. Education in customer management is lacking, despite the efforts of many institutes, associations and forums. Key concepts (eg simpler ones such as decile analysis, or more complex ones such as customer value forecasting or measuring the success of retention management against control groups) are still not widely used. Outbound contact strategies are surprisingly rare. Customer service competencies are undervalued. Lifetime value is used patchily. Enquiry follow up is random and ad hoc. The list goes on. Good training does exist in some companies.

Direct or database marketing principles (particularly in relation to analysis, campaign management, lead management, customer retention and measurement) underpin good CM. But in many companies direct marketing has a poor image and this can lead to rejection of its norms.

\section{There remains a belief that IT is a panacea}

IT is not the panacea it is often thought to be. 'Global CRM in 90 days' is a widely advertised claim by a large IT company - how misleading. IT can enable and even drive the business model, but a company must define its CM model first. This then defines the role of IT. The rest of the organisation must be aligned and must change, at least a little. All this takes time. Data are the building blocks of many companies' CM management efforts. The authors' research ${ }^{15}$ shows data management remains one of the stumbling blocks to creating value in this area.

\section{Poor implementation of customer management projects}

CMAT $^{\mathrm{TM}}$ assessments regularly reveal unrealistic roadmaps, irrelevant business cases, poor (often absent) programme management and many failed projects.

\section{It is not all doom and gloom}

Despite the above, there are many examples of stunningly effective 
Table 2: The size of the investment, the four to one rule

\begin{tabular}{|c|c|c|c|c|c|}
\hline Company & $\begin{array}{l}\text { Overall size } \\
\text { of company } \\
\text { (turnover) } \\
€ \mathrm{~m}\end{array}$ & $\begin{array}{l}\text { CM investments } \\
\text { as percentage } \\
\text { of turnover } \\
\%\end{array}$ & $\begin{array}{l}\text { Benefit as } \\
\text { percentage } \\
\text { of turnover } \\
\%\end{array}$ & $\begin{array}{l}\text { Size of } \\
\text { benefit } \\
€ m\end{array}$ & $\begin{array}{l}\text { Return on } \\
\text { investment } \\
\text { (ROI) }\end{array}$ \\
\hline Company 1 & 735.0 & 2 & 8.5 & 62.8 & 4.3 \\
\hline Company 2 & 7.8 & 15.5 & 52.6 & 4.1 & 3.4 \\
\hline Company 3 & $11,700.0$ & 0.5 & 2.1 & 240.0 & 4.1 \\
\hline Company 4 & 610.0 & 2 & 8.3 & 50.4 & 4.2 \\
\hline
\end{tabular}

practices in companies assessed by the authors. Analysis of CMAT $^{\mathrm{TM}}$ scores shows that the following characteristics, activities and foci are most closely associated with high (top quartile) scores and overall business performance.

Each area of CM identified by the CMAT $^{\mathrm{TM}}$ model correlates significantly with business performance. ${ }^{16}$ There is some difference between CM performance between countries and sectors, but there is a marked similarity in the characteristics of successful CM across sectors and geographies.

\section{THE BUSINESS CASE FOR CUSTOMER MANAGEMENT}

Customer management starts with analysis and planning. ${ }^{17}$ This includes planning for:

- Retention

- Efficiency

- Acquisition

- Penetration.

These are referred to as the REAP measures. Investment in the REAP measures can provide a four to one return on investment ${ }^{18}$ for well-managed programmes (see Table 2). This is based on tracking four case studies over a three-year period.

It is important to note from the example given in Table 2 that:
- size is turnover at the start of the period, and all benefits are calculated in NPV terms

- CM investment as percentage of turnover is exactly as stated

- benefit as percentage of turnover is the total net benefit across the three-year forecast period

- return on investment is defined as the total increase in revenue relative to the total additional investment applied.

Table 2 appears to show a relationship between the level of investment and the benefits from improved acquisition, retention and development (there are no general rules for efficiency gains, as these depend so much on how efficient the company was before the investment). That is, in general, increased revenue is around four times the original investment. Though this is a small sample, this figure is consistent with that for other projects the authors have implemented, in both

business-to-business and business-to-consumer companies. On the basis of this insight, it is suggested that if a business invested $\$ 50 \mathrm{~m}$ in $\mathrm{CM}$ and the project is managed properly the company should expect an eventual $\$ 200 \mathrm{~m}$ return. While this is a useful rule of thumb, it does not guide a company on how much it should invest and it also disguises the relative benefits to be gained from companies 
with a different starting competence in customer management.

\section{Lower quartile performers}

Companies that are in the bottom quartile in CM performance would typically operate a classic product organisational model with strong product management disciplines and focus on product sales. Investment for these companies should not be biased towards IT as so often happens. These companies need to invest across the enterprise in all aspects of the QCi customer management model. Failure to invest will lead to continued underperformance as the authors' correlation work suggests. These companies are likely targets for a takeover or risk going out of business.

\section{High quartile performers}

High quartile performers in CM will be high business performers. They will already have a well-developed people and systems infrastructure and a mature, customercentric culture. All the characteristics of top performing companies mentioned in this report will be in place. These companies 'know who they are', what they offer and which customers they are managing. They are flexible in their planning and their decision-making ability allows them to react to market changes quickly. Their IT systems and culture will be customer focused, so that, for example, their databases will contain the full customer 'context' across any channel and transaction, data capture will be consistent across channels, a common set of business rules will apply, for example offering prompts as to how an individual contact or transaction should be handled, irrespective of medium (ie on the Web, in the call centre or sales force, in partner intermediaries or in retail outlets).

\section{CONCLUSION}

Companies that are in the bottom quartile in CM performance face a difficult and uncertain future. If they do nothing, they are unlikely to survive. In order to improve they need to make substantial investment across all areas of CM. Higher quartile performers will need to remain alert to make sure they remain ahead. Overall customer management performance remains disappointing, but the payback for those that invest in the 'right things' can be substantial. Investment in technology alone without an in-depth understanding of current capability will not suffice. Technology is merely one of the enabling and supporting elements of CM and will not, by itself, cure other shortcomings.

\section{References}

1 From a presentation by Maoz, M. (2001) Gartner Spring Summit, March 19th-21st, Chicago, Gartner Research.

2 Woodcock, N. and Starkey, M. (2001) 'I wouldn't start from here: Finding a way in CRM projects', Journal of Database Marketing, Vol. 9, No. 1.

3 Kintz, E. (2001) 'Get ROI, not hype', Line56, San Francisco, September.

4 Goldberg, H. (2001) '10 ways to avoid CRM pitfalls', B2B, Chicago, 17th September.

5 Toplonksi, T. (2001) 'The impact of 11 September on the CRM software vendor market', 29th October, note number SOFT-WW-DP-0040, Gartner.

6 'Delivering value from CRM - Forsyth, Gartner, et. al. tell you how!!', www.crm-forum. com, accessed 27th November 2001.

7 Doyle, P. (2001) 'Value based marketing: Marketing strategies for corporate growth and shareholder value', Wiley.

8 Woodcock, N. (2000) 'Does CRM performance correlate with business performance?', The Journal of Interactive Marketing, April.

9 Woodcock, N., Starkey, M. and Stone, M. (2000) 'The customer management scorecard: The state of the nation', Business Intelligence.

10 Ibid.

11 Woodcock, N., Starkey, M., Stone, M., Weston, P. and Ozimek, J. (2002) 'State of the nation II: 2002 - How companies are creating and destroying economic value through customer management', QCi Assessment Ltd. 
12 Ibid, ss. 5-12.

13 Woodcock (2000) op. cit.

14 Woodcock, N. (2001) 'Companies think in boxes', to be published December.

15 Stone, M., Findlay, G., Evans, M., and Leonard, M. (2001) 'Data chaos - a court case waiting to happen', International Journal of Customer
Relationship Management, Vol. 4, No. 2, pp. 169-184.

16 Woodcock (2000) op. cit.

17 Woodcock, Starkey, and Stone (2000) op. cit.

18 Woodcock, Starkey, Stone, Weston and Ozimek (2002) op. cit. s. 14, 'The Business Case for Customer Management'. 